\title{
Atomic layer deposition of InN using trimethylindium and ammonia plasma
}

\author{
Petro Deminskyi ${ }^{a}$, Polla Rouf, Ivan G. Ivanov, Henrik Pedersen \\ Department of Physics, Chemistry and Biology, Linköping University, SE-58183 Linköping, \\ Sweden \\ a) Electronic mail: petro.deminskyi@liu.se
}

InN is a low band gap, high electron mobility semiconductor material of interest to optoelectronics and telecommunication. Such applications require the deposition of uniform crystalline InN thin films on large area substrates, with deposition temperatures compatible with this temperature-sensitive material. As conventional chemical vapor deposition (CVD) struggles with the low temperature tolerated by the InN crystal, we hypothesize that a time-resolved, surface-controlled CVD route could offer a way forward for InN thin film deposition. In this work, we report atomic layer deposition of crystalline, wurtzite $\mathrm{InN}$ thin films using trimethylindium and ammonia plasma on Si (100). We found a narrow ALD window of $240-260{ }^{\circ} \mathrm{C}$ with a deposition rate of $0.36 \AA /$ cycle and that the flow of ammonia into the plasma is an important parameter for the crystalline quality of the film. X-ray photoelectron spectroscopy measurements shows nearly stoichiometric InN with low carbon level $(<1$ atomic $\%)$ and oxygen level $(<5$ atomic \%) in the film bulk. The low carbon level is attributed to a favorable surface chemistry enabled by the $\mathrm{NH}_{3}$ plasma. The film bulk oxygen content is attributed to oxidation upon exposure to air via grain boundary diffusion and possibly by formation of oxygen containing species in the plasma discharge. 


\section{INTRODUCTION}

Indium nitride ( $\mathrm{InN}$ ) has interesting optical and electronic properties such as low energy band-gap $(0.7 \mathrm{eV})$, very high electron mobility $\left(4000 \mathrm{~cm}^{2} / \mathrm{V}\right)$ and high electron saturation velocity $\left(4.2 \times 10^{7} \mathrm{~cm} / \mathrm{s}\right)$ making it an attractive material for e.g. high frequency electronics and lasers. ${ }^{1,2}$ Chemical vapor deposition (CVD) of InN using trimethylindium, $\left(\mathrm{In}\left(\mathrm{CH}_{3}\right)_{3}\right.$, TMI) and ammonia $\left(\mathrm{NH}_{3}\right)$, as precursors is limited by the thermal stability of the InN crystal above $500{ }^{\circ} \mathrm{C}$, as it decomposes to In metal and $\mathrm{N}_{2}$ gas at those temperatures. ${ }^{3}$ This combined with the low reactivity of $\mathrm{NH}_{3}$ at temperatures below $500{ }^{\circ} \mathrm{C},{ }^{4}$ force the use of $\mathrm{N} / \mathrm{In}$ ratios as high as $10^{5}$ in $\mathrm{CVD}$ of $\mathrm{InN} .^{5}$ It was speculated that a better route would be a surface-controlled CVD process where the role of the gas phase chemistry is strongly reduced or even eliminated. A time-resolved CVD route, where the In and N precursors are separated in time to promote a kinetically-controlled pulsed process, could be such a route. Therefore, a time-resolved CVD process in the form of atomic layer deposition (ALD) for InN was explored. Given the low reactivity of ammonia at low temperatures, a nitrogen containing plasma has been used in previous studies for ALD of both polycrystalline and epitaxial InN on different planar and 3D substrate topographies. ${ }^{6-10}$ All previous literature on InN ALD uses TMI as In precursor. It has been shown that $A r-\mathrm{N}_{2}$ plasma and TMI, results in a poorly functioning surface chemistry for removal of methyl groups from the surface, and requires very long plasma exposures, up to $120 \mathrm{~s} .{ }^{8,10} \mathrm{Nepal}$ et al. reported a correlation between changes in the gas-phase chemistry of the plasma source and InN film; higher nitrogen atom concentration within the plasma source is correlated with smoother InN films. Furthermore, low $\mathrm{N}_{2}$ flow appears to aid reduction of the carbon content. ${ }^{9}$ To the best of our knowledge, the use of ammonia plasma as an alternative nitrogen source has not been investigated and reported for InN ALD. The approach to InN ALD employing 
$\mathrm{In}\left(\mathrm{CH}_{3}\right)_{3}$ is interesting since the $\mathrm{NH}_{\mathrm{x}}$ species present in the plasma are believed to remove hydrocarbons from the surface. ${ }^{11}$ In this work, we report on the self-limiting growth of crystalline InN thin films by ALD using TMI and ammonia plasma. Additionally, the impact of ammonia plasma power and ammonia flow on film quality has been investigated, analyzed and described in detail.

\section{EXPERIMENTAL}

\section{A. Film deposition}

Depositions were carried out in a Picosun R-200 atomic layer deposition tool with a total pressure of $6 \mathrm{hPa}$. The schematics of the experimental setup is shown in Figure 1a. The ICP plasma is generated within a quartz tube surrounded by a cylindrical RF coil. The substrate holder stage is located downstream $(\sim 70 \mathrm{~cm})$ from the plasma source. ALD of InN were conducted within the temperature range of $200-360{ }^{\circ} \mathrm{C}$ on $2 \times 2 \mathrm{~cm} \mathrm{Si}(100)$ using $\mathrm{NH}_{3}$ plasma, and $\mathrm{In}\left(\mathrm{CH}_{3}\right)_{3}$, kept in a stainless-steel bubbler mounted in a Peltier element with the temperature set at $23{ }^{\circ} \mathrm{C} . \mathrm{N}_{2}(99.999 \%)$ was used as the carrier gas for trimethylindium precursor delivery to the reaction chamber. The plasma was ignited using a co-flow of $100 \mathrm{sccm} \operatorname{Ar}(99.9997 \%)$ together with the $\mathrm{NH}_{3}(99.999990 \%)$ flow. $\mathrm{N}_{2}$, Ar, and $\mathrm{NH}_{3}$ gases were further purified by getter filters. The gas mixture was fed into the system downstream from the ICP source. Unless stated otherwise, the $\mathrm{NH}_{3}$ flow rate was $50 \mathrm{sccm}$ and the plasma power in the range from $2400 \mathrm{~W}$ to $2800 \mathrm{~W}$ with $10 \mathrm{~s}$ plasma pulses. An AB-type ALD process was used (Fig. 1b) with $\mathrm{TMI}$ and $\mathrm{NH}_{3}$ plasma. The TMI vapor pressure is given by Eqn. $(1)^{12}$ :

$$
\log P(\text { Torr })=10.98-\frac{3204}{T(K)}
$$


which gives the vapor pressure of TMI to $1.46 \mathrm{hPa}$ at $23{ }^{\circ} \mathrm{C}$, which is lower than the total pressure in the deposition chamber. We therefore used a bubbler "fill-empty" approach for the TMI exposure: a first pulse with a high nitrogen carrier gas flow of $300 \mathrm{sccm}$ adds some nitrogen gas to the TMI bubbler and slightly increases its pressure; a second pulse uses a more moderate nitrogen flow of $100 \mathrm{sccm}$ to release the overpressure in the TMI bubbler. The two pulses are separated by $10 \mathrm{~s}$ to allow gas mixing in the bubbler. The pulse times used in the fill-empty of the process was $4 \mathrm{~s}$ for the fill sub-pulse and a variable time for the empty sub-pulse. A 10 s purge was used after the TMI fill-empty pulse sequence followed by $10 \mathrm{~s} \mathrm{NH}_{3}$ plasma exposure, unless otherwise noted, and $6 \mathrm{~s}$ purge to complete the ALD cycle.

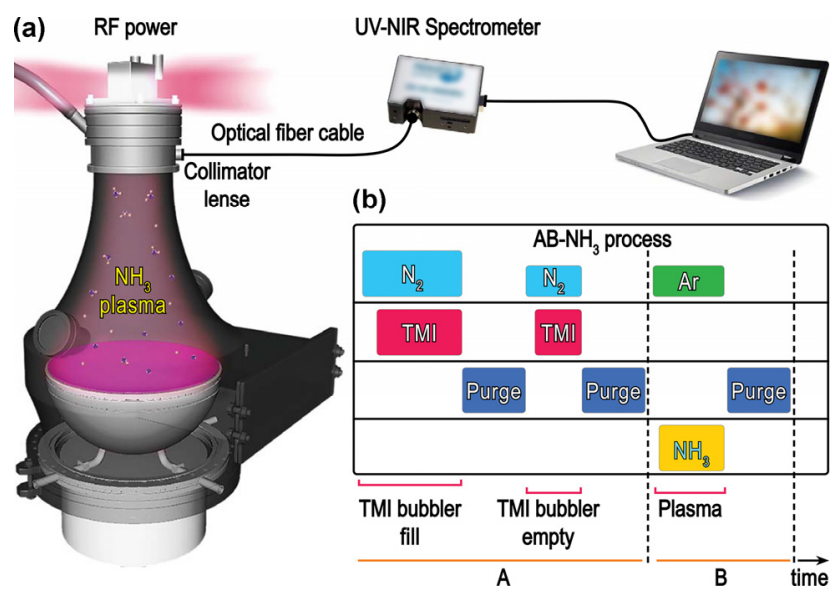

FIG. 1. (a) Schematic illustration of the experimental setup of the Picosun plasma enhanced ALD reactor. An optical fiber coupled to a Mechelle 900 UV-NIR spectrometer monitors plasma emission within the ICP. (b) Schematic depiction of the AB-type $\mathrm{NH}_{3}-$ plasma based ALD process investigated in this study.

Prior to deposition, the Si (100) substrate was cleaned in acetone, 2-propanol and deionized (DI) water with further sample drying under $\mathrm{N}_{2}$ flow. Silicon substrates were 
transferred into the ALD chamber which was held at the set deposition temperature. An in-situ surface pretreatment with $2800 \mathrm{~W} \mathrm{~N}_{2}$ plasma for 2 min was conducted to make the substrate surface somewhat more nitrogen-rich before $\mathrm{InN}$ growth. Post-deposition annealing of some InN films was done in the reactor prior to unloading the sample by increasing the temperature to $500{ }^{\circ} \mathrm{C}$ for 2 hours at $10 \mathrm{sccm} \mathrm{N}_{2}$ flow.

\section{B. Film characterization}

X-ray diffraction (XRD) analysis was performed by using Empyrean PanAnalytical X'Pert system with a Philips Bragg-Brentano diffractometer that was equipped with a parallel beam detector. The $\mathrm{Cu} \mathrm{K} \alpha$ radiation source $(\lambda=0.154[06] \mathrm{nm})$ was operated at $40 \mathrm{kV}$ and $40 \mathrm{~mA}$. The grazing incidence X-ray diffraction (GIXRD) mode was used to minimize the intensity from the substrate peaks since the films were limited in thickness. The incoming beam angle, $\omega$, was $0.5^{\circ}$. Data were obtained within the $2 \theta$ range of $20-90^{\circ}$, which were performed using $0.02^{\circ}$ step size and $1 \mathrm{~s}$ step time. Interplanar spacing $\left(d_{h k l}\right)$ values were calculated from peaks position using Bragg's law. Lattice parameters $a$ and $c$ were calculated by substituting $d_{h k l}$ values using Eqn. (2).

$$
\frac{1}{d^{2}}=\frac{4}{3}\left(\frac{h^{2}+h k+k^{2}}{a^{2}}\right)+\frac{l^{2}}{c^{2}}
$$

Thickness of the deposited films where measured by a PanAnalytical X'Pert Pro in the X-ray reflectometry (XRR) mode. Growth rates were calculated by dividing film thicknesses by the number of ALD cycles. Surface morphologies of InN thin films were studied using a high-resolution LEO 1550 Gemini field emission SEM. Chemical composition and bonding states of the films were determined by an Axis Ultra DLD instrument from Kratos Analytical X-ray photoelectron spectroscopy (XPS) with a base

pressure of $1.1 \times 10^{-9}$ Torr $\left(1.5 \times 10^{-7} \mathrm{~Pa}\right)$ and monochromatic $\mathrm{Al} \mathrm{Ka}$ source 
$(\mathrm{h} v=1486.6 \mathrm{eV})$. Depth profiling was carried out using an Ar ion sputter beam with an acceleration voltage, spot size, and a sputtering time duration of $0.5 \mathrm{kV}, 300 \times 700 \mu \mathrm{m}$, and $400 \mathrm{~s}$ respectively. Spectra deconvolution and quantification were performed using CasaXPS software.

The Raman spectra are measured in a micro-Raman setup using excitation of $532 \mathrm{~nm}$. The laser (with power of $1 \mathrm{~mW}$ to avoid thermal damage to the sample) is focused on the sample to a spot of diameter $\sim 0.85 \mu \mathrm{m}$ using a microscope objective with magnification $100 \mathrm{X}$ and numerical aperture 0.95 . The detection of the spectra is done with a single monochromator (Jobin-Yvon, Model HR460) equipped with a 1200 grooves/mm grating and a CCD camera. The resulting resolution of the system is $\sim 2.5 \mathrm{~cm}^{-1}$. Owing to the small thickness of the InN layers, the spectrum is strongly dominated by the Raman scattering from the Si-substrate. Nevertheless, it is possible to distinguish clearly the contribution from the InN layer, as will be discussed later.

Ellipsometric spectra of the films were recorded in the wavelength range of 200 $1500 \mathrm{~nm}$ at three angles of incidence $\left(65^{\circ}, 70^{\circ}\right.$, and $\left.75^{\circ}\right)$ by using a variable angle spectroscopic ellipsometer (J.A. Woollam). Optical constants of the InN thin films were modeled by the Tauc-Lorentz function as an oscillator. The absorption coefficient,

$$
\alpha(\lambda)=\frac{4 \pi k(\lambda)}{\lambda}
$$

was calculated from the values of the extinction coefficient $k(\lambda)$ determined from the measured ellipsometry data. Optical band gap $\left(E_{\mathscr{g}}\right)$ is expressed by the following equation for direct band gap materials and was analytically extracted via extrapolation of the linear part of the absorption spectrum to $(\alpha E)^{2}=0$, where $E$ denotes the photon energy.

$$
\alpha E=A\left(E-E_{g}\right)^{1 / 2}
$$




\section{Plasma characterization}

Optical emission spectroscopy (OES) was performed using the Mechelle 900 Spectrometer with cooled digital 12-bit CCD camera system with a wavelength range of UV-NIR (200-1100 nm), mounted perpendicularly to the plasma source. Light emitted from the $\mathrm{NH}_{3}$ plasma was collected and directed to a monochromator with an optical fiber cable. The optical emission from the plasma was measured just after the ICP source in the gas flow direction, before the plasma reached the substrate. Data was analyzed with consideration for spectrometer spectral resolution of 900 (meaning that two wavelengths separated by $1 / 900$ of the wavelength can be resolved). The measure of resolution is a constant of the instrument, which implies that the fractional wavelength resolution does not vary with the wavelength. The plasma diagnostics were focused on the formation of $\mathrm{NH}, \mathrm{N}_{2}, \mathrm{~N}_{2}{ }^{+}$, and $\mathrm{H}$, at different plasma power, $\mathrm{NH}_{3}$ flow rate, and their influence on $\mathrm{InN}$ properties.

\section{RESULTS AND DISCUSSION}

The InN deposition process was studied by varying the second sub-pulse, i.e. the empty sub-pulse of the TMI fill-empty pulse between 0 and $6 \mathrm{~s}$, while keeping the $\mathrm{NH}_{3}$ pulse at $10 \mathrm{~s}$, or by keeping the empty sub-pulse at $3.5 \mathrm{~s}$ and varying the $\mathrm{NH}_{3}$ plasma pulse between 0 and 20 s. For all experiments, the purge times (6 s), deposition temperature $\left(300{ }^{\circ} \mathrm{C}\right)$ and plasma power $(2400 \mathrm{~W})$ were kept constant. The conventional ALD cycles with a single step TMI pulse did not afford uniform InN growth on $\operatorname{Si}(100)$ substrates. We ascribe this to insufficient TMI vapor delivery. Figure 2a shows the effect of the time for both the TMI pulse and the $\mathrm{NH}_{3}$ plasma pulse on the growth rate of InN. A second set of experiments (Fig. 2b) studied the effect of 
the deposition temperature on the InN growth. Here the TMI empty pulse was $3 \mathrm{~s}$ and the $\mathrm{NH}_{3}$ plasma pulse $10 \mathrm{~s}$ while varying the temperature from $200{ }^{\circ} \mathrm{C}$ to $360{ }^{\circ} \mathrm{C}$.

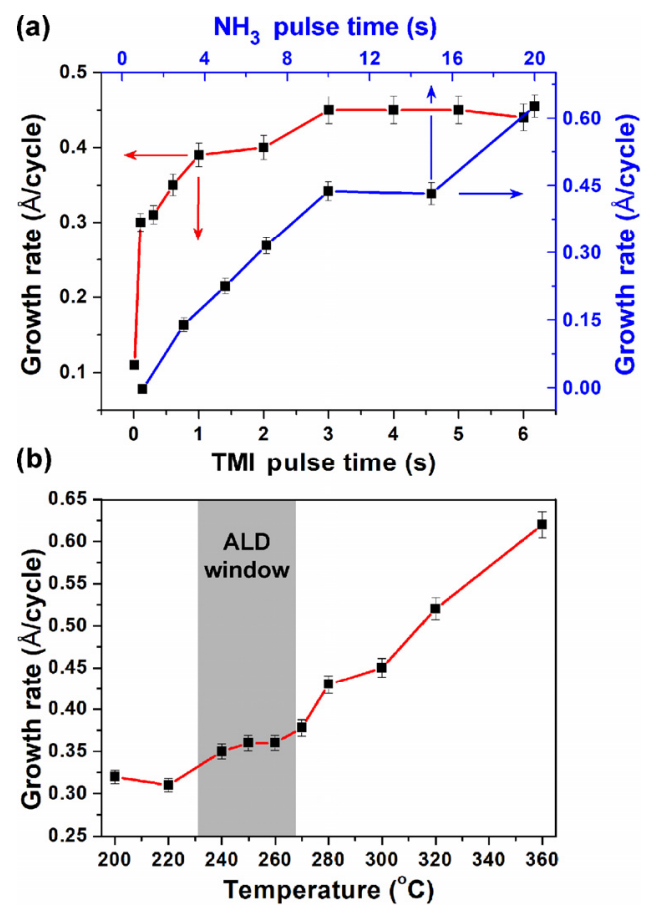

FIG. 2. (a) Effect of TMI and $\mathrm{NH}_{3}$ precursors dose time on $\mathrm{InN}$ growth rate with $2400 \mathrm{~W}$ plasma power at $300{ }^{\circ} \mathrm{C}$ with $10 \mathrm{~s} \mathrm{NH}_{3}$ pulse (red line), and $2800 \mathrm{~W}$ plasma power at $320^{\circ} \mathrm{C}$ with $3.5 \mathrm{~s}$ TMI pulse (blue line). (b) Effect of temperature on growth rate, for $3 \mathrm{~s}$ TMI pulse and $10 \mathrm{~s} \mathrm{NH}_{3}$ pulse.

The results on InN growth rate as a function of a growth temperature (within 200 $360{ }^{\circ} \mathrm{C}$ ) show that $\mathrm{InN}$ is deposited at $200{ }^{\circ} \mathrm{C}$ with $0.32 \AA$ cycle. The growth rate increases with temperature and shows a narrow plateau of $0.36 \AA$ cycle at $240-260{ }^{\circ} \mathrm{C}$ which could be regarded as a narrow ALD temperature window. The growth rate then further increases to reach $0.62 \AA /$ cycle at $360^{\circ} \mathrm{C}$ (Fig. 2b). This indicates saturation in growth rate both as a function of the precursor pulse time and of the temperature. The ALD-cycle for further experiments were set to: TMI $4 \mathrm{~s}$ fill sub-pulse and $3.5 \mathrm{~s}$ empty sub-pulse, $10 \mathrm{~s}$ purge, $10 \mathrm{~s} \mathrm{NH}$ plasma and $6 \mathrm{~s}$ purge. 
Figure 3 displays the SEM images of InN morphology for various durations of the TMI empty sub-pulses. Without the use of fill-empty for the TMI pulse, the deposition process leads to growth of isolated islands (Fig. 3a). By only adding a $0.1 \mathrm{~s}$ empty subpulse, the islands coalesce (Fig. 3b). Longer empty sub-pulses lead to growth of continuous films consisting of smaller and smaller grains with longer time for the empty sub-pulse.
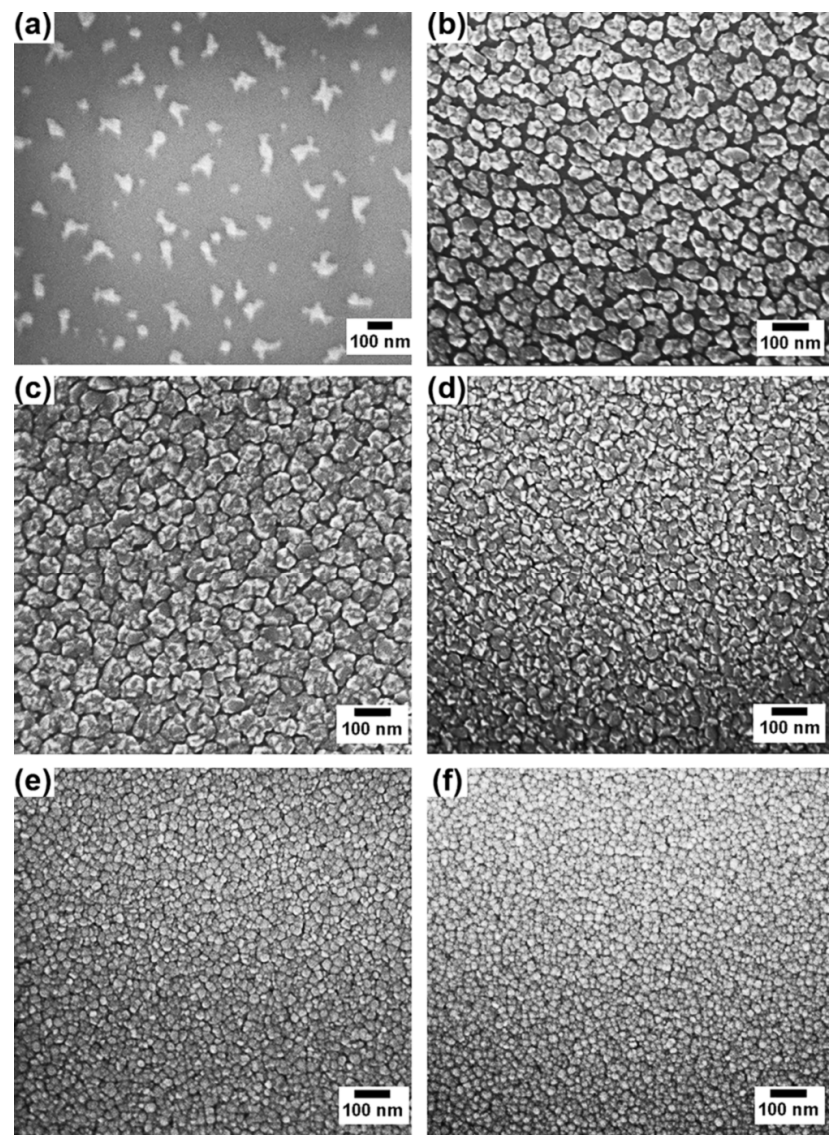

FIG. 3. Top view SEM images of InN surfaces for various times of the TMI empty subpulse: $0 \mathrm{~s}(\mathrm{a}), 0.1 \mathrm{~s}(\mathrm{~b}), 0.3 \mathrm{~s}(\mathrm{c}), 0.6 \mathrm{~s}(\mathrm{~d}), 1 \mathrm{~s}(\mathrm{e})$, and $6 \mathrm{~s}$ (f). 

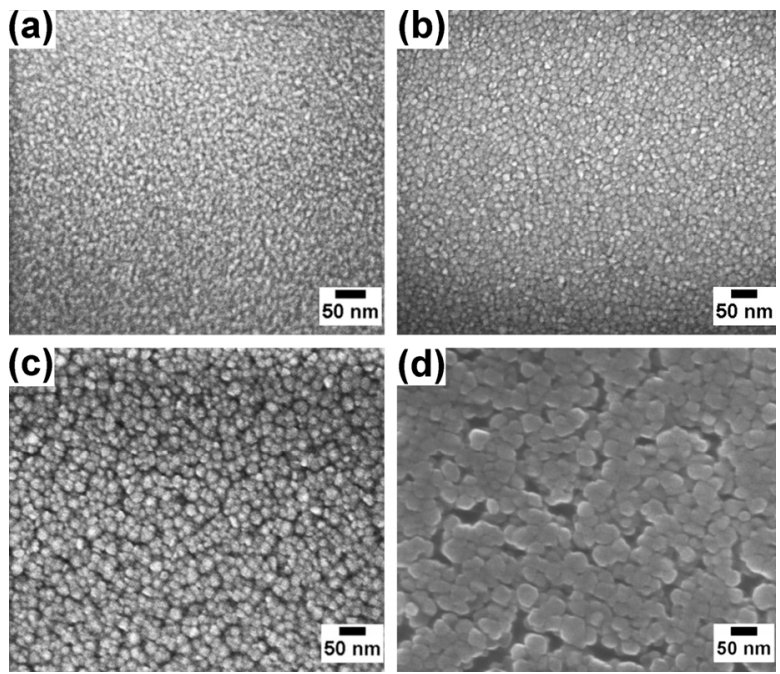

FIG. 4. Top view SEM images of InN films deposited at $200{ }^{\circ} \mathrm{C}(\mathrm{a}), 260^{\circ} \mathrm{C}$ (b), $300^{\circ} \mathrm{C}$ (c), and $360^{\circ} \mathrm{C}(\mathrm{d})$ with $2400 \mathrm{~W}$ plasma power.

Figure 4 displays the SEM images of crystalline grain structures of InN films deposited at $200{ }^{\circ} \mathrm{C}, 260{ }^{\circ} \mathrm{C}, 300{ }^{\circ} \mathrm{C}$, and $360{ }^{\circ} \mathrm{C}$ with $2400 \mathrm{~W}$ plasma power. Changing the temperature leads to the formation of larger grains and their coalescence into дфкпук clusters. Figure 5 displays the SEM images of crystalline grain structures of InN films deposited with $2400 \mathrm{~W}, 2500 \mathrm{~W}, 2700 \mathrm{~W}$, and $2800 \mathrm{~W}$ plasma power at $320^{\circ} \mathrm{C}$. Changing the plasma power does not have a clear impact on the film morphology, while the GIXRD shows a change in crystalline quality (Fig. 7b). The growth rate changes somewhat with the plasma power from $0.51 \AA$ /cycle at $2400 \mathrm{~W}$ to $0.47 \AA$ /cycle at 2800 W. Figure 6 shows SEM images of InN films deposited with $50 \mathrm{sccm}, 75 \mathrm{sccm}$, $100 \mathrm{sccm}$ ammonia flow under $2800 \mathrm{~W}$ plasma power at $320^{\circ} \mathrm{C}$. Changing ammonia flow has slight impact on the film morphology in terms of grains crystallization. The GIXRD results and variations of the $a$ - and $c$-axis lattice constants show a change in crystalline quality of $\mathrm{InN}$ (Fig. $7 \mathrm{~b}$ ). The growth rate changes somewhat with the plasma 
power from $0.44 \AA /$ cycle at $50 \mathrm{sccm}$ to $0.33 \AA$ cycle at $100 \mathrm{sccm}$. This could be explained by an increased density of hydrogen radicals in ammonia plasma with higher ammonia flow rate as hydrogen radicals has been shown to reduce the growth rate of InN films. $^{13}$
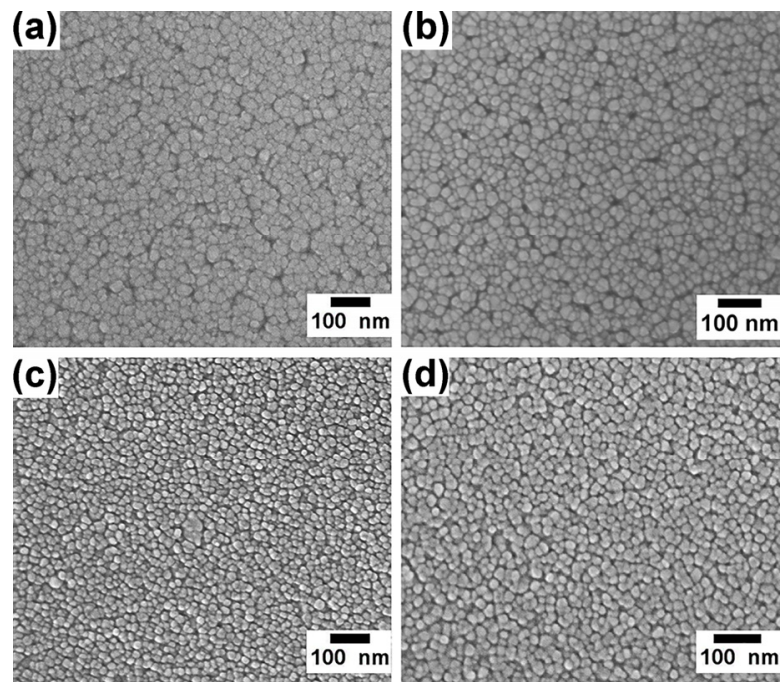

FIG. 5. Top view SEM images of InN films deposited at $2400 \mathrm{~W}$ (a), $2500 \mathrm{~W}$ (b), $2700 \mathrm{~W}$ (c), and $2800 \mathrm{~W}(\mathrm{~d})$ plasma power at $320^{\circ} \mathrm{C}$.
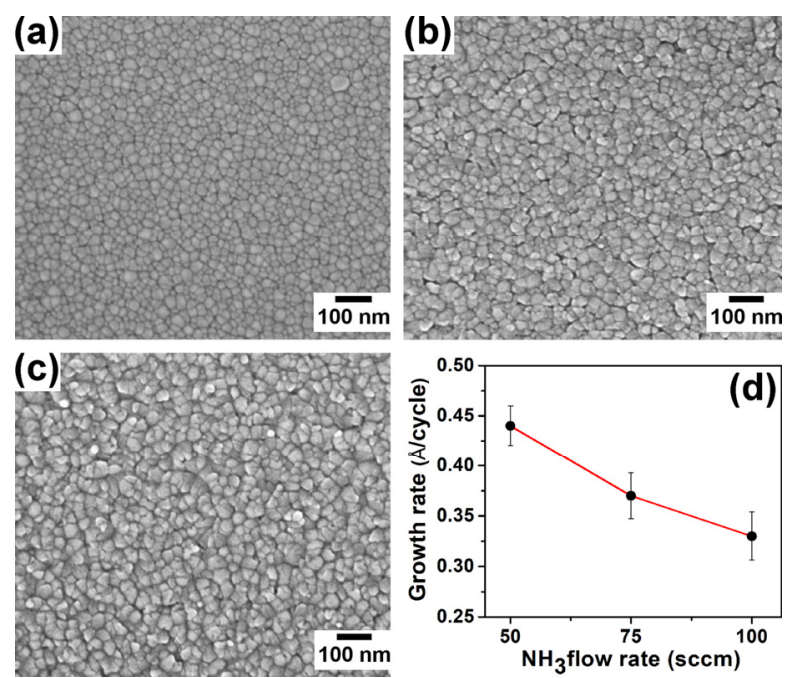

FIG. 6. Top view SEM images of InN surfaces for $50 \mathrm{sccm}$ (a), $75 \mathrm{sccm}$ (b) and $100 \mathrm{sccm}$ (c) of $\mathrm{NH}_{3}$ flow. (d) Effect of $\mathrm{NH}_{3}$ flow on $\mathrm{InN}$ growth rate with $2800 \mathrm{~W}$ plasma power at $320^{\circ} \mathrm{C}$. 
The crystallinity of the InN films studied by GIXRD is shown in Figure 7a for $18 \mathrm{~nm}, 26 \mathrm{~nm}$ and $31 \mathrm{~nm}$ thick films deposited with $2400 \mathrm{~W}$ plasma power at $240{ }^{\circ} \mathrm{C}$, $320^{\circ} \mathrm{C}$, and $360^{\circ} \mathrm{C}$, respectively. Figure $7 \mathrm{~b}$ shows the GIXRD measurements of $26 \mathrm{~nm}$, $25 \mathrm{~nm}$ and $23 \mathrm{~nm}$ thick $\mathrm{InN}$ films deposited at $320{ }^{\circ} \mathrm{C}$ with $2400 \mathrm{~W}, 2500 \mathrm{~W}$, and $2800 \mathrm{~W}$ plasma power, respectively. The (100), (002), (011), (012), (110), (013), (020), (004) and (023) reflections ${ }^{14,15}$ of the hexagonal wurtzite phase of $\operatorname{InN}$ were observed. We note that changes in deposition temperature and plasma power do not alter the peak positions, while the intensity of the peaks increases with increasing deposition temperature. The lattice parameters $a$ and $c$ were calculated using Eqn. (2) and the $2 \theta$ positions of the (002) and (011) reflections (Fig. 8). Interplanar spacing $\left(d_{h k l}\right)$ values of (002) and (011) planes were calculated from Bragg's law. The relation between the strain in the $c$-axis direction $\varepsilon_{\mathrm{c}}=\left|\left(c-c_{0}\right) / c_{0}\right|$ and that in the direction of the $a$-axis $\varepsilon_{\mathrm{a}}=\left|\left(a-a_{0}\right) / a_{0}\right|$, (where $c_{0}=5.7033 \AA$ and $a_{0}=3.5378 \AA$ correspond to epitaxial InN) gives values $\sim 0.004$ for $\varepsilon_{\mathrm{c}}$ and 0.002 for $\varepsilon_{\mathrm{a}}$ indicating almost fully relaxed and strain free InN films (Fig. 8 a and b). ${ }^{16,17}$ 

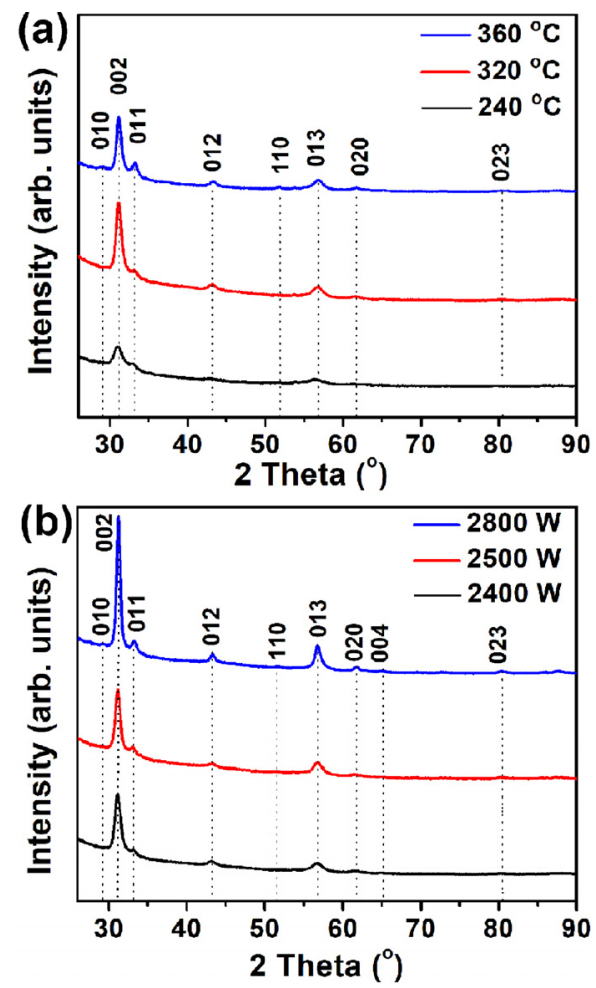

FIG. 7. GIXRD pattern of $\operatorname{InN}$ film deposited on $\operatorname{Si}(100)$ substrate (a) under $240{ }^{\circ} \mathrm{C}$, $320^{\circ} \mathrm{C}, 360{ }^{\circ} \mathrm{C}$ deposition temperatures and $2400 \mathrm{~W}$ plasma power; (b) under $2400 \mathrm{~W}$, $2500 \mathrm{~W}, 2800 \mathrm{~W}$ plasma power and $320^{\circ} \mathrm{C}$ deposition temperature.

GIXRD of $40 \mathrm{~nm}$ and $49 \mathrm{~nm} \mathrm{InN}$ thin films grown with $2800 \mathrm{~W} \mathrm{NH}_{3}$ plasma power at $320^{\circ} \mathrm{C}$, and $360{ }^{\circ} \mathrm{C}$ with an added annealing at $500{ }^{\circ} \mathrm{C}$ for $2 \mathrm{~h}$ indicated that the annealing affected the relative intensities of the peaks. For the $\mathrm{InN}$ films grown at $320^{\circ} \mathrm{C}(\sim 40 \mathrm{~nm})$, and $360{ }^{\circ} \mathrm{C}(\sim 49 \mathrm{~nm})$, the $c$-axis lattice parameter was $5.7140 \AA$ and $5.7058 \AA$ while the $a$-axis lattice parameter was $3.5198 \AA$ and $3.5254 \AA$, showing that the annealing further reduces the stress in the material. GIXRD of InN films grown with different ammonia flows (Fig. 9) shows that the diffraction peak intensities increases with higher ammonia flow and that the $a$ and $c$-axis lattice have values of $3.54271 \AA$ and $5.69981 \AA$ at the optimal ammonia flow, displaying an increased crystalline quality of $\mathrm{InN}$ with higher ammonia flow in the plasma. 


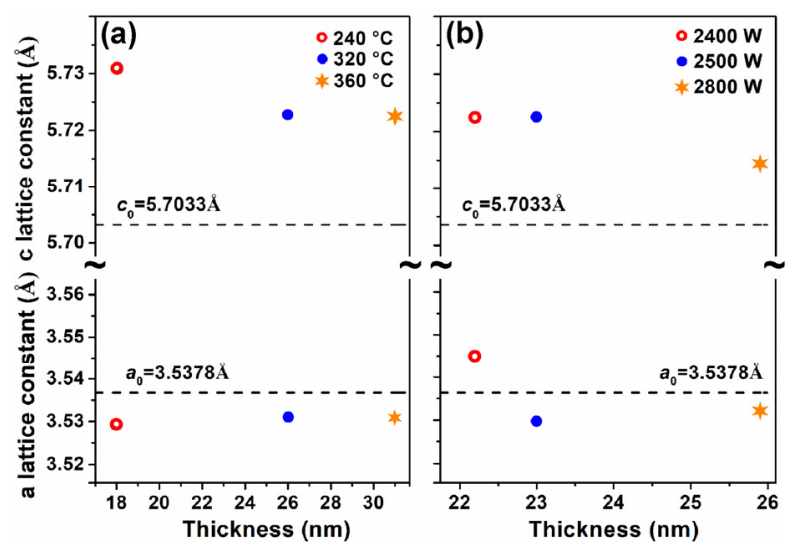

FIG. 8. Variations of the a- and c-axis lattice constants of In- and N-growth face InN films with the film thickness at (a) different temperatures at $2400 \mathrm{~W}$ ammonia plasma, and (b) different plasma power at $320^{\circ} \mathrm{C}$. Dashed lines show strain-free lattice constant of the aand c-axis. $^{16}$
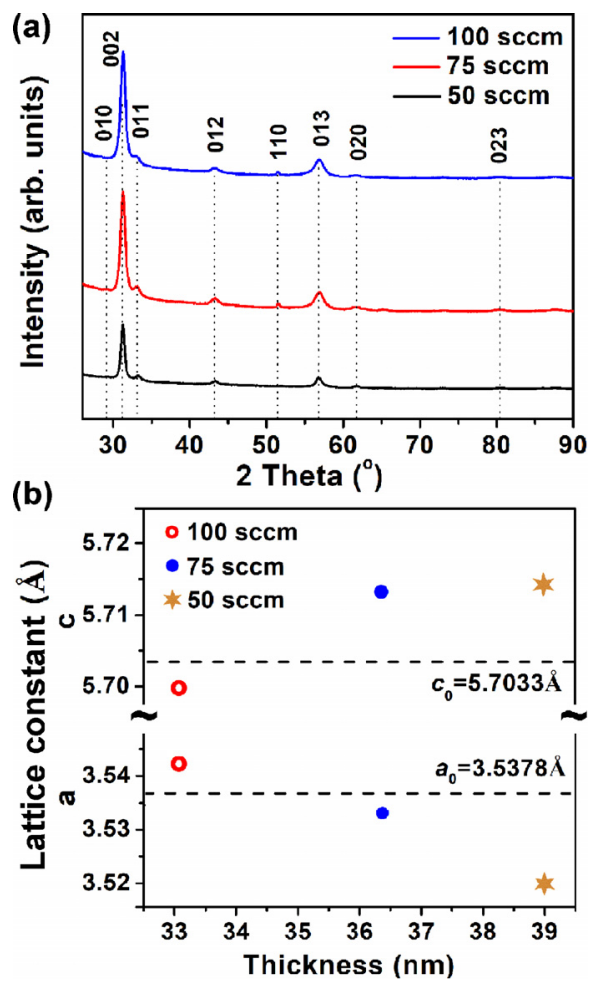

FIG. 9. GIXRD pattern (a) and variations of the $a$ - and $c$-axis lattice constants (b) of InN film deposited on $\mathrm{Si}(100)$ substrate at $50 \mathrm{sccm}, 75 \mathrm{sccm}$ and $100 \mathrm{sccm}$ of $\mathrm{NH}_{3}$ flow with $2800 \mathrm{~W}$ plasma power at $320^{\circ} \mathrm{C}$. 
XPS measurements were conducted on InN thin films grown at $320^{\circ} \mathrm{C}, 320^{\circ} \mathrm{C}$ annealed at $500{ }^{\circ} \mathrm{C}$, and $360{ }^{\circ} \mathrm{C}$ annealed at $500{ }^{\circ} \mathrm{C}$. Figure 10 shows the narrow scan XPS of In $3 \mathrm{~d}$ and $\mathrm{N}$ 1s spectra for different growth and post-treatment temperatures which refer to the bulk film $\left(t_{\text {etch }}=400 \mathrm{~s}\right)$. The surface of the $\mathrm{InN}$ film is oxidized and carbonized ( $\sim 30 \%$ oxygen and $\sim 25 \%$ carbon), which is likely to originate from postdeposition exposure to atmosphere. For compositional depth profile measurements, InN thin films were etched by $\mathrm{Ar}^{+}$ions in steps of $400 \mathrm{~s}$ to obtain elemental composition from the bulk of the films. While carbon is detected on the films surface, the carbon signal is below the XPS detection limit in the bulk of the InN films. This is indicative of a wellfunctioning surface chemistry with the ammonia plasma, aiding in the removal of the methyl groups on the surface. ${ }^{18}$ Significant amounts of oxygen $(\mathrm{O})$ were detected in the bulk of the film, (Table I). This could be caused by oxygen containing species formed in the quartz tube of the inductively coupled plasma source. ${ }^{19}$ The polycrystalline nature of the films could also lead to oxidation of the film bulk via oxygen diffusion in grain boundaries. It was found that a change in growth temperature from $320^{\circ} \mathrm{C}$ to $360{ }^{\circ} \mathrm{C}$ led to a reduction in oxygen content from 24 at.\% to 17 at.\% while the $\mathrm{N}$ content increased from 29 at.\% to 34 at.\%. Figure 4 (a-d) and Figure 7 (a) show larger grain size and higher crystalline quality with higher deposition temperature, indicating that the lower oxygen content could be caused by less oxygen diffusion into the film with the larger crystallites. The In/ $\mathrm{N}$ ratio was computed from the composition of $\mathrm{InN}$ thin films (Table I) indicating nitrogen deficient films. 
TABLE I. Elemental compositions (at.\%) and $\mathrm{In} / \mathrm{N}$ ratios obtained from XPS survey spectra.

\begin{tabular}{|c|c|c|c|c|c|c|c|c|c|c|}
\hline $\begin{array}{l}\text { Deposition } \\
\text { temperature }\end{array}$ & & & Surf: & & & & & Bulk & & \\
\hline & In & $\mathrm{N}$ & $\mathrm{O}$ & $\mathrm{C}$ & $\begin{array}{l}\text { In/N } \\
\text { Ratio }\end{array}$ & In & $\mathrm{N}$ & $\mathrm{O}$ & $\mathrm{C}$ & $\begin{array}{l}\text { In } / \mathrm{N} \\
\text { Ratio }\end{array}$ \\
\hline $320^{\circ} \mathrm{C}$ & 29.33 & 18.69 & 27.11 & 24.85 & 1.57 & 47.5 & 28.9 & 23.57 & - & 1.64 \\
\hline $\begin{array}{l}320^{\circ} \mathrm{C} \text { annealed } \\
\text { at } 500^{\circ} \mathrm{C}\end{array}$ & 28.59 & 15.06 & 30.98 & 25.36 & 1.9 & 45.96 & 28.64 & 25.38 & - & 1.59 \\
\hline $\begin{array}{l}360^{\circ} \mathrm{C} \text { annealed } \\
\text { at } 500^{\circ} \mathrm{C}\end{array}$ & 28.2 & 17.86 & 26.99 & 26.93 & 1.58 & 49.4 & 33.81 & 16.78 & - & 1.46 \\
\hline
\end{tabular}

The In $3 d$ XPS spectrum (Fig. 10) show two spin-orbit doublets; In $3 d_{5 / 2}$ and In $3 \mathrm{~d}_{3 / 2}$ (with intensity ratio $3: 2$ ) for $\mathrm{InN}$ thin films grown at $320^{\circ} \mathrm{C}$, grown at $320{ }^{\circ} \mathrm{C}$ annealed at $500{ }^{\circ} \mathrm{C}$, and grown at $360{ }^{\circ} \mathrm{C}$ annealed at $500{ }^{\circ} \mathrm{C}$. The sub-peaks of the $\mathrm{In} 3 \mathrm{~d}_{5 / 2}$ and In $3 \mathrm{~d}_{3 / 2}$ correspond to In-N bonds and In-O bonds (Table II). The $\mathrm{N} 1 \mathrm{~s}$ XPS spectrum reveal a dominant sub-peak corresponding to N-In bonds which is more intense than the sub-peak corresponding to $\mathrm{N}-\mathrm{O}$ bonds. A slight shift from higher to lower binding energies for $\mathrm{N} 1 \mathrm{~s}$ peaks was observed when the deposition temperature was increased. This was correlated to the lower stress and lower oxygen content in the InN film (Fig. 9 a, b) and stoichiometries closer to 1:1 (In:N) ratio that were obtained at higher deposition temperatures. 
TABLE II. Binding energies obtained from XPS survey spectra of InN in the bulk. ${ }^{8,20}$

\begin{tabular}{ccccccc}
\hline \hline $\begin{array}{c}\text { Deposition } \\
\text { temperature }\end{array}$ & & \multicolumn{5}{c}{ Binding energy, eV } \\
\hline & \multicolumn{2}{c}{ In-N } & & In-O & N-In & N-O \\
$\mathbf{3 2 0}{ }^{\circ} \mathbf{C}$ & 443.6 & 451.1 & 444.3 & 451.6 & 396.4 & 396.8 \\
$\begin{array}{c}\mathbf{3 2 0}{ }^{\circ} \mathbf{C} \text { annealed } \\
\text { at 500 }\end{array}$ & 443.7 & 451.3 & 444.4 & $451.6 \mathrm{eV}$ & 396.4 & 396.8 \\
$\begin{array}{c}\mathbf{3 6 0}{ }^{\circ} \mathbf{C} \text { annealed } \\
\mathbf{a t ~ 5 0 0 ~}^{\circ} \mathbf{C}\end{array}$ & 443.5 & 451.0 & 444.2 & 451.6 & 396.7 & 397.3 \\
\hline \hline
\end{tabular}

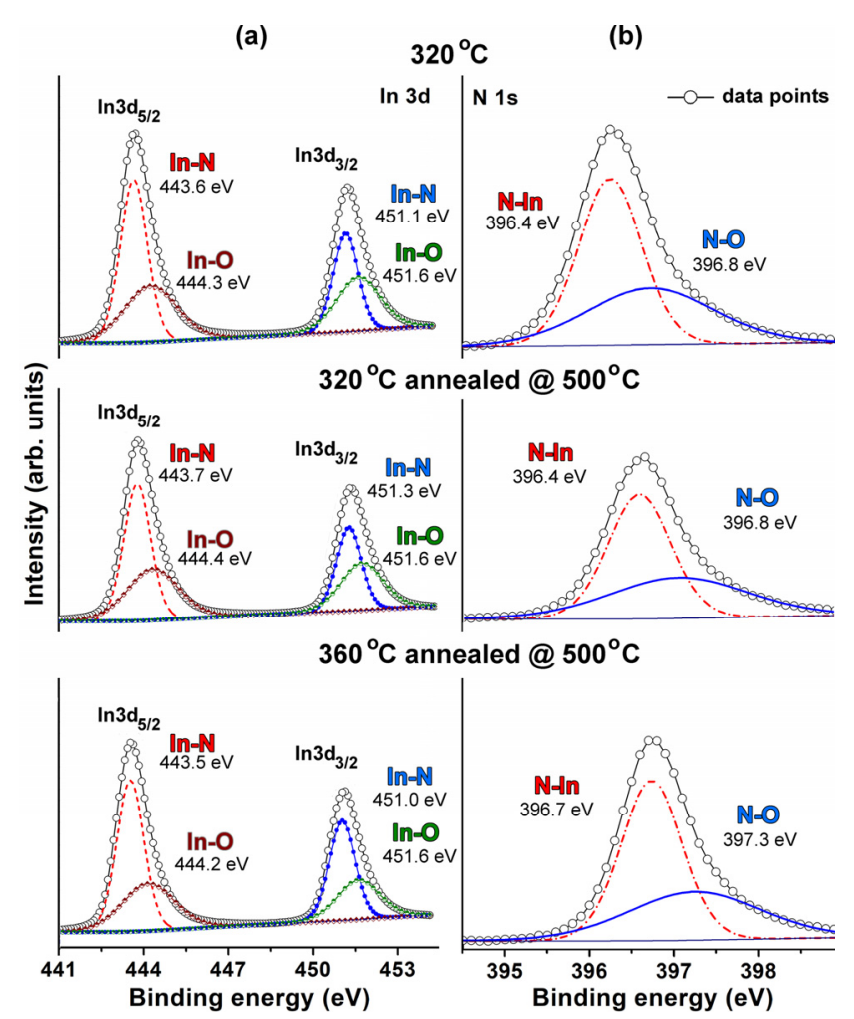

FIG. 10. High-resolution XPS spectra of (a) In 3d, (b) N 1s peaks of InN films deposited at temperatures. The spectra are taken after sputtering to represent the bulk of the films.

XPS measurements on $\mathrm{InN}$ films grown under $2800 \mathrm{~W}$ plasma power at $320^{\circ} \mathrm{C}$ show that a change in ammonia flow rate from $50 \mathrm{sccm}$ to $75 \mathrm{sccm}$ and further to $100 \mathrm{sccm}$, led to 
a significant reduction in oxygen content from $\sim 24$ at. $\%$ to $\sim 5$ at. $\%$ while the $\mathrm{N}$ content increased from $\sim 29$ at. $\%$ to $\sim 44$ at. $\%$. The In/ $\mathrm{N}$ ratio (Table III) indicating the shift from highly nitrogen deficient films with $\mathrm{In} / \mathrm{N}$ ratio of 1.64 (for $50 \mathrm{sccm}$ ammonia flow) to a stoichiometry closer to 1 with $\mathrm{In} / \mathrm{N}$ ratio of $\sim 1.1$ (for $75 \mathrm{sccm}$ and $100 \mathrm{sccm}$ ). The lower oxygen content in the film bulk could be caused by the slightly larger crystalline grains formed with higher ammonia flow (Fig. 6 a-c), which would lead to less grain boundary diffusion of oxygen. (Fig. 9). Another plausible reason for the lower oxygen content in the film bulk could be that the higher ammonia flow would reduce the impact of any oxygen containing species in the plasma discharge since a higher ammonia flow would render a lower partial pressure of the oxygen containing species.

TABLE III. Elemental compositions (at.\%) and In/ $\mathrm{N}$ ratios obtained from XPS survey spectra.

\begin{tabular}{llllllllllll}
\hline $\begin{array}{c}\text { Deposition } \\
\text { temperature }\end{array}$ & \multicolumn{4}{c}{ Surface } & \multicolumn{5}{c}{ Bulk } \\
\hline & In & $\mathrm{N}$ & $\mathrm{O}$ & $\mathrm{C}$ & $\begin{array}{l}\text { In/N } \\
\text { Ratio }\end{array}$ & In & $\mathrm{N}$ & $\mathrm{O}$ & $\mathrm{C}$ & $\begin{array}{l}\text { In/N } \\
\text { Ratio }\end{array}$ \\
$\mathbf{5 0} \mathbf{~ s c c m}$ & 29.3 & 18.7 & 27.1 & 24.8 & 1.57 & 47.5 & 28.9 & 23.5 & - & 1.64 \\
$\mathbf{7 5} \mathbf{~ s c c m}$ & 22.9 & 21.7 & 25.8 & 29.4 & 1.05 & 46.2 & 41.2 & 11.5 & 1.0 & 1.12 \\
$\mathbf{1 0 0} \mathbf{~ s c c m}$ & 23.9 & 22.5 & 25.3 & 28.2 & 1.06 & 50.78 & 43.8 & 4.8 & 0.53 & 1.15 \\
\hline \hline
\end{tabular}




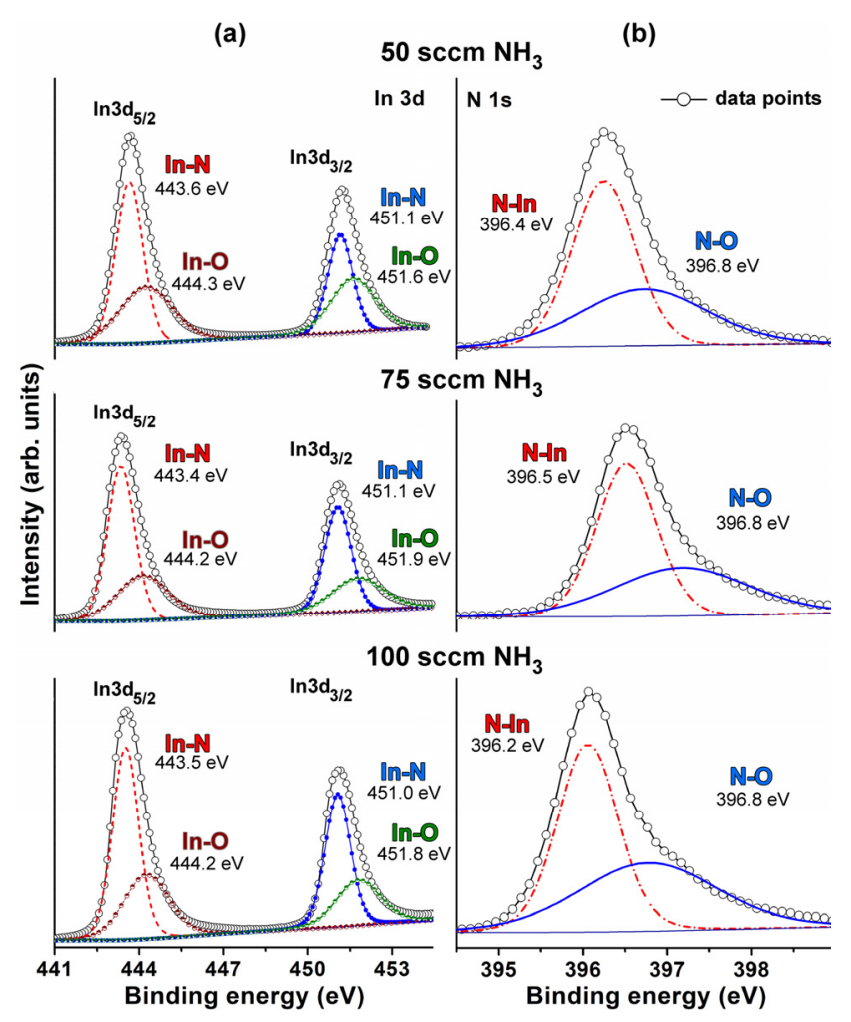

FIG. 11. High-resolution XPS spectra of (a) In 3d, (b) $N$ 1s peaks of InN films deposited with $50 \mathrm{sccm}, 75 \mathrm{sccm}, 100 \mathrm{sccm}$ of ammonia flow at $320^{\circ} \mathrm{C}$ and $2800 \mathrm{~W}$ of plasma power. The spectra are taken after sputtering to represent the analysis of $\operatorname{InN}$ in the bulk.

In $3 \mathrm{~d}$ XPS spectrum (Fig. 11) again show two spin-orbit doublets; In $3 \mathrm{~d}_{5 / 2}$ and In $3 \mathrm{~d}_{3 / 2}$ for InN thin films grown at $50 \mathrm{sccm}, 75 \mathrm{sccm}, 100 \mathrm{sccm}$ of ammonia flow. The sub-peaks of the In $3 d_{5 / 2}$ and In $3 d_{3 / 2}$ correspond to In-N and In-O bonds (Table IV). The $\mathrm{N}$ 1s XPS spectrum reveal a dominant sub-peak corresponding to N-In bonds which is more intense than the sub-peak corresponding to $\mathrm{N}-\mathrm{O}$ bonds. The binding energies as a function of different ammonia flow show slight shift to lower energies for peaks corresponding to In-N bonds. This is correlated to the lower oxygen content in the InN film for higher ammonia flow. 
TABLE IV. Binding energies obtained from XPS survey spectra of InN in the bulk. ${ }^{8,20}$

\begin{tabular}{ccccccc}
\hline \hline $\mathbf{N H}_{3}$ flow rate & \multicolumn{5}{c}{ Binding energy, eV } \\
\hline & \multicolumn{2}{c}{ In-N } & \multicolumn{2}{c}{ In-O } & N-In & N-O \\
$\mathbf{5 0} \mathbf{~ s c c m}$ & 443.6 & 451.1 & 444.3 & 451.6 & 396.4 & 396.8 \\
$\mathbf{7 5} \mathbf{~ s c c m}$ & 443.4 & 451.1 & 444.2 & $451.9 \mathrm{eV}$ & 396.5 & 396.8 \\
$\mathbf{1 0 0} \mathbf{~ s c c m}$ & 443.5 & 451.0 & 444.2 & 451.8 & 396.2 & 396.8 \\
\hline \hline
\end{tabular}

To further understand the deposition process, we collected OES spectra during InN deposition at $320^{\circ} \mathrm{C}$ with plasma powers of $2400 \mathrm{~W}$ and $2800 \mathrm{~W}$ and with $\mathrm{NH}_{3}$ flow rates of $50 \mathrm{sccm}, 75 \mathrm{sccm}$ and $100 \mathrm{sccm}$. A carrier flow of $100 \mathrm{sccm}$ Ar was used for all experiments (see Fig. 12 and Table V). The emission spectra for the $2400 \mathrm{~W}$ and $2800 \mathrm{~W}$ of $\mathrm{NH}_{3}$ plasmas were found to be very similar with the same peaks positions and almost the same peaks intensities. The prominent lines were observed as a line related to $\mathrm{NH}$ at $336.1 \mathrm{~nm}$, a line related to $\mathrm{N}_{2}$ at $357.1 \mathrm{~nm}$, a shoulder related to $\mathrm{CN}$ at $388.5 \mathrm{~nm}$, and a line related to $\mathrm{N}_{2}{ }^{+}$at $391.4 \mathrm{~nm}$. The $\mathrm{NH}, \mathrm{N}_{2}$, and $\mathrm{N}_{2}{ }^{+}$species were not observed to increase with increased plasma power but with increased $\mathrm{NH}_{3}$ flow rate (Fig. 12a, and Fig. 12b). The emission peaks at $\sim 336 \mathrm{~nm}$ and $337 \mathrm{~nm}$ for different plasma power and $\mathrm{NH}_{3} / \mathrm{Ar}$ flow rate, indicate the presence of the excited $N H, N_{2}$ radicals that corresponds to $\mathrm{A}^{3} \Pi \rightarrow \mathrm{X}^{3} \Sigma$ and $\mathrm{C}^{3} \Pi_{\mathrm{u}} \rightarrow \mathrm{B}^{3} \Pi_{\mathrm{g}}$ transitions, corroborating the presence of $\mathrm{NH}_{\mathrm{x}}(\mathrm{x}<3)$ and $\mathrm{N}_{2}$ species. ${ }^{21,22}$ In addition to $\mathrm{NH}, \mathrm{N}_{2}, \mathrm{~N}_{2}{ }^{+}$, and $\mathrm{CN}$ detected in $\mathrm{NH}_{3} /$ Ar plasma, the $\mathrm{H}_{\gamma}, \mathrm{H}_{\beta}$, and $\mathrm{H}_{\alpha}$ lines were detected at $434.0 \mathrm{~nm}, 486.1 \mathrm{~nm}$, and $\sim 656.3 \mathrm{~nm}$ (Table V). The presence of $\mathrm{N}_{2}, \mathrm{~N}_{2}{ }^{+}$and $\mathrm{H}$ radicals can be attributed to the collisions of $\mathrm{NH}$ radicals: $\mathrm{NH}+\mathrm{NH} \rightarrow \mathrm{N}_{2}+2 \mathrm{H}\left(k=1.2 \times 10^{-}\right.$ $\left.{ }^{15} \mathrm{~m}^{3} \mathrm{~s}^{-1}\right) .{ }^{23} \mathrm{CN}$ species are attributed to the plasma-surface interactions; species created at 
the surface in reactions with the ammonia plasma and surface bound methyl groups, which are then further decomposed in the plasma making them visible as $\mathrm{CN}$ in OES measurement, and then removed from the chamber during the purge step. ${ }^{24}$ The OES measurements could not find any optically active oxygen containing species and can thus not confirm any formation of oxygen containing species in the plasma discharge in the quartz tube. It is important to note that the OES measurements only detect optically active species and possible oxygen containing species might not be optically active. The OES measurements are thus not suggesting that oxygen containing species are not formed in the plasma discharge.

TABLE V. Spectral characteristics of species detected in the $\mathrm{NH}_{3} /$ Ar plasma.

\begin{tabular}{|c|c|c|c|}
\hline Species & $\lambda, \mathbf{n m}$ & Transition & Reference \\
\hline NH & 336.1 & $\mathrm{~A}^{3} \Pi \rightarrow \mathrm{X}^{3} \Sigma^{-}(3360 \AA$ system $)$ & 23 \\
\hline $\mathbf{N}_{2}$ & $337.1, \quad 357.7$ & $\mathrm{C}^{3} \Pi_{\mathrm{u}} \rightarrow \mathrm{B}^{3} \Pi_{\mathrm{g}}$ Second positive & $23,25,26$ \\
\hline $\mathbf{N}_{2}^{+}$ & $391.4,427.6$ & $\mathrm{~B}^{2} \Sigma_{\mathrm{u}}^{+} \rightarrow \mathrm{X}^{2} \Sigma_{\mathrm{g}}^{+}$ & $27-21,25$ \\
\hline $\mathbf{C N}$ & 388.88 & $\mathrm{~B}^{2} \Sigma_{\mathrm{u}}^{+} \rightarrow \mathrm{X}^{2} \Sigma_{\mathrm{g}}^{+}$ & 25 \\
\hline \multirow[t]{3}{*}{$\mathbf{H}_{\gamma}, \mathbf{H}_{\beta}, \mathbf{H}_{\alpha}$} & $434.0, \quad 486.1, \quad 656.29$ & $\mathrm{n}(>2) \rightarrow \mathrm{n}=2$ (Balmer line) & 26 \\
\hline & $695.6, \quad 750.3,911.1$ & $4 p^{2}[1 / 2] \rightarrow 4 s^{2}[3 / 2]^{0}$ & \\
\hline & $705.9, \quad 738.0, \quad 763.48$ & $4 p^{2}[3 / 2] \rightarrow 4 s^{2}[3 / 2]^{0}$ & \\
\hline \multirow[t]{3}{*}{ Ar } & $772.5, \quad 827.3$ & $4 p^{2}[1 / 2] \rightarrow 4 s^{2}[1 / 2]^{0}$ & 25 \\
\hline & 795.2 & $4 p^{2}[3 / 2] \rightarrow 4 s^{2}[1 / 2]^{0}$ & \\
\hline & $801.7, \quad 811.6, \quad 842.2$ & $4 p^{2}[5 / 2] \rightarrow 4 s^{2}[3 / 2]^{0}$ & \\
\hline
\end{tabular}



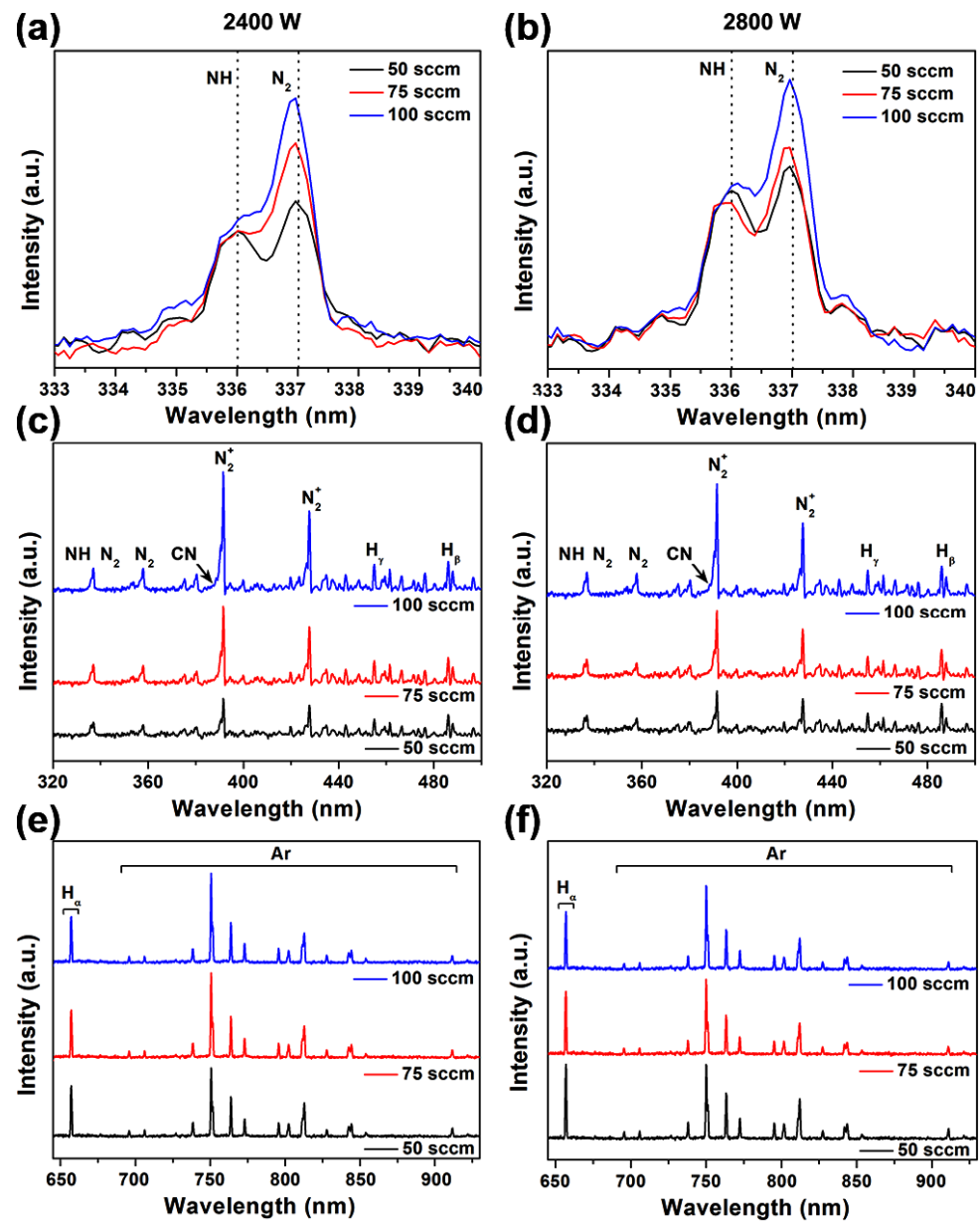

Fig. 12. Optical emission spectra for $\mathrm{NH}_{3}$ and $\mathrm{Ar}$ plasmas at $2400 \mathrm{~W}, 2800 \mathrm{~W}$ and $50 \mathrm{sccm}, 75 \mathrm{sccm}$, and $100 \mathrm{sccm}$ of $\mathrm{NH}_{3}$ over the wavelength range of (a, b) $333 \mathrm{~nm}-$ $340 \mathrm{~nm},(\mathrm{c}, \mathrm{d}) 320 \mathrm{~nm}-500 \mathrm{~nm}$, and (e, f) $645 \mathrm{~nm}-930 \mathrm{~nm}$.

InN thin film ( $39 \mathrm{~nm}$ thick) grown at $320^{\circ} \mathrm{C}$ and $2800 \mathrm{~W}$ was studied by Raman scattering measurements (Fig. 13). Reference spectra from bare Si substrate are also displayed for comparison (bottom curves in each panel). Expanded views of the spectral regions $150-490 \mathrm{~cm}^{-1}$, and $530-650 \mathrm{~cm}^{-1}$ are shown in Figure $13(\mathrm{a}-\mathrm{d})$. According to the factor group analysis six optical modes can be observed for crystalline $\mathrm{InN}$ in the firstorder Raman spectrum: $\mathrm{A}_{1}(\mathrm{TO}), \mathrm{A}_{1}(\mathrm{LO}), \mathrm{E}_{1}(\mathrm{TO}), \mathrm{E}_{1}(\mathrm{LO}), \mathrm{E}_{2}$ (high), and $\mathrm{E}_{2}(\mathrm{low}) .{ }^{27}$ In our 
Raman scattering experiments, the $A_{1}(T O)$ and $A_{1}(L O)$ modes of hexagonal InN were observed at wave numbers of $447 \mathrm{~cm}^{-1}$ and $586 \mathrm{~cm}^{-1}$ together with peaks ascribed to yet unidentified defects at $180 \mathrm{~cm}^{-1}$ and $375 \mathrm{~cm}^{-1} \cdot{ }^{28,29}$ The band peaking at $436 \mathrm{~cm}^{-1}$ is due to second-order Raman scattering from the Si substrate. ${ }^{30}$ The sharp rise in parts (c, d) of the Figure 13 is due to the wings of the strong Raman peak of the substrate at $520 \mathrm{~cm}^{-1}$. Furthermore, the Si-substrate related mode at $520 \mathrm{~cm}^{-1}$ has obviously shoulders on the left- and right-hand side that covers the broad range from $\sim 460 \mathrm{~cm}^{-1}$ to $\sim 580 \mathrm{~cm}^{-1}$ where other phonon modes such as $\mathrm{E}_{1}(\mathrm{TO}), \mathrm{E}_{2}{ }^{\text {high }}$ could exist. ${ }^{31-33}$ Thereby, the Raman spectra also support that crystalline $\mathrm{InN}$ dominated by hexagonal phase was grown on $\mathrm{Si}$.
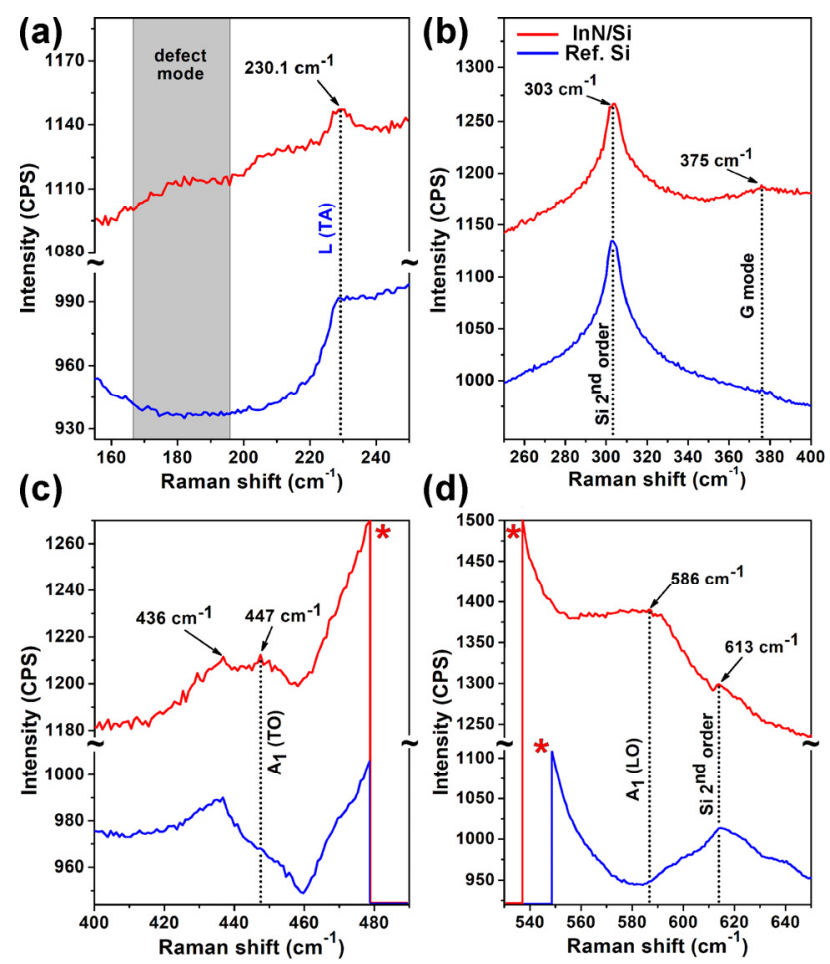

FIG. 13. Raman spectra of InN film grown at $320{ }^{\circ} \mathrm{C}$ and $2800 \mathrm{~W}$ of ammonia plasma for $150-250 \mathrm{~cm}^{-1}$ (a), $250-400 \mathrm{~cm}^{-1}$ (b), $400-490 \mathrm{~cm}^{-1}$ (c), and $530-650 \mathrm{~cm}^{-1}$ (d). Two prominent modes typical for wurtzite h-InN structure are observed. $(*$ denotes peak from the $\mathrm{Si}$ substrate). The bottom curve in each panel displays the spectrum of bare $\mathrm{Si}$ substrate in the corresponding region, which serves as a reference. 
Using ellipsometric spectroscopy, we obtained refractive index $(n)$ and extinction coefficient $(k)$ of InN films deposited at $320^{\circ} \mathrm{C}$ and $360^{\circ} \mathrm{C}$ (Fig. 14a). Refractive index was measured to be 2.6 and 2.7 at $650 \mathrm{~nm}$, while it was measured to be 1.95 and 2.03 at $1400 \mathrm{~nm}$, respectively. These values are in good agreement with the reported values for polycrystalline h-InN thin films. ${ }^{8,34}$ An increase in thickness of $\mathrm{InN}$ from $39 \mathrm{~nm}$ to $48 \mathrm{~nm}$ leads to an increase in refractive index by 0.1 and 0.08 at $650 \mathrm{~nm}$ and $1400 \mathrm{~nm}$, respectively. This improvement might be attributed to film densification with the increase in thickness of the film. Extinction coefficient $(k)$ of $\operatorname{InN}$ films, measured to be 0.36 and 0.41 at $600 \mathrm{~nm}$, these values decrease drastically within the wavelength range of 600 $900 \mathrm{~nm}$, and reaches rather insignificant level at longer wavelengths.
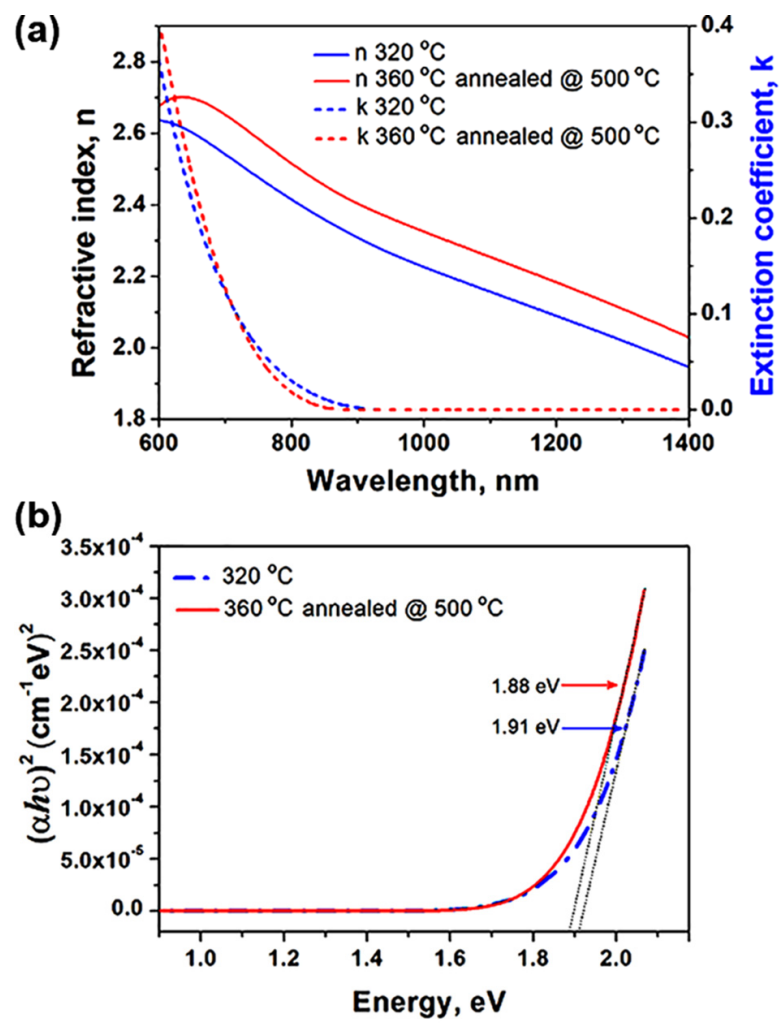

FIG. 14. (a) Optical constants $\mathrm{n}$ and $\mathrm{k}$ of $\mathrm{InN}$ thin film deposited on $\mathrm{Si}(100)$ at $320^{\circ} \mathrm{C}$ and $360^{\circ} \mathrm{C}$. (b) Absorption spectra of the same InN samples. 
Figure 14(b) shows $(\alpha h v)^{2}$ vs. hv plot, which is obtained from spectroscopic ellipsometry measurement and related data analysis as explained in the experimental section. Straight line segment of the plot was extrapolated to the abscissa (black arrows shown in the inset of Fig. 14b) which reveals the band edge of InN thin films as $1.91 \mathrm{eV}$ and $1.88 \mathrm{eV}$ at $320^{\circ} \mathrm{C}$ and $360{ }^{\circ} \mathrm{C}$. These results are in a good agreement to the results $(1.9 \mathrm{eV})$ obtained for InN thin films grown via ALD using TMI and $\mathrm{N}_{2}$ plasma. ${ }^{8}$

\section{IV.SUMMARY AND CONCLUSIONS}

We show the development of a self-limiting $\mathrm{InN}$ growth process utilizing trimethylindium and ammonia plasma in a remote plasma ALD system at $240-360^{\circ} \mathrm{C}$ and 2400-2800 W plasma power. We find a narrow thermal ALD window between $240{ }^{\circ} \mathrm{C}$ and $260{ }^{\circ} \mathrm{C}$ with a growth rate of $0.36 \AA$ cycle. The deposited $\mathrm{InN}$ films are polycrystalline by GIXRD with carbon content below 1 at.\% in the film bulk, indicative of a well-functioning ALD surface chemistry. We find that the $\mathrm{NH}_{3}$ flow through the plasma discharge is an important parameter for depositing films with high crystalline quality and low impurity levels. The InN films were found to be nearly stoichiometric by XPS with In/ $\mathrm{N}$ ratio of 1.1 and $<5 \%$ oxygen. We ascribe the film bulk oxygen content to film oxidation caused by grain boundary diffusion of oxygen upon exposure to air and possibly also by oxygen containing species possibly formed in the plasma discharge done in a quartz tube. The ammonia plasma was found to contain $\mathrm{NH}, \mathrm{CN}, \mathrm{N}_{2}, \mathrm{~N}_{2}^{+}$and hydrogen radicals by OES. The refractive index of the InN films was measured to be 2.7 at $650 \mathrm{~nm}$, and 2 at $1400 \mathrm{~nm}$, respectively. The optical band gap of the $\mathrm{InN}$ films was measured to about $1.9 \mathrm{eV}$. 


\section{ACKNOWLEDGMENTS}

This project was founded by the Swedish foundation for Strategic Research through the project "Time-resolved low temperature CVD for III-nitrides" (SSF-RMA 15-0018) and by the Knut and Alice Wallenberg foundation through the project "Bridging the $\mathrm{THz}$ gap" (KAW 2013.0049). IGI acknowledges support from the VR (project VR 201605362). PD acknowledges the Carl Trygger Foundation for a post-doctoral scholarship at Linköping University and Laurent Souqui for his kind suggestions during OES measurements.

${ }^{1}$ A. G. Bhuiyan, A. Hashimoto, and A. Yamamoto, J. Appl. Phys. 94, 2779 (2003).

${ }^{2}$ B. A. Andreev, K. E. Kudryavtsev, A. N. Yablonskiy, D. N. Lobanov, P. A. Bushuykin, L. V. Krasilnikova, E. V. Skorokhodov, P. A. Yunin, A. V. Novikov, V. Yu Davydov \& Z. F. Krasilnik, Scientific Reports 8, 9454 (2018).

${ }^{3}$ S. V. Ivanov, T. V. Shubina, V. N. Jmerik, J. Crystal Growth 403, 83 (2014).

${ }^{4}$ K. Rönnby, S. C. Buttera, P. Rouf, S. Barry, L. Ojamäe, and H. Pedersen, (2018). Preprint https://doi.org/10.26434/chemrxiv.7067687.v1

${ }^{5}$ S. Ruffenach, M. Moret, O. Briot, and B. Gil, Phys. Status Solidi A 207, 9 (2010).

${ }^{6}$ H. Peng, X. Feng, J. Gong, W. Wang, H. Liu, Z. Quan, S. Pan, L. Wang, Applied Surface Science 459, 830 (2018).

${ }^{7}$ A. Haider, P. Deminskyi, M. Yilmaz, K. Elmabruk, I. Yilmazd, and N. Biyikli, J. Mater. Chem. C 6, 6471 (2018).

${ }^{8}$ A. Haider, S. Kizir, N. Biyikli, AIP Adv. 6, 045203 (2016).

${ }^{9}$ D. Boris, V. Anderson, N. Nepal, S. Johnson, Z. Robinson, A. Kozen, C. Eddy Jr., and S. Walton, J. Vac. Sci. Technol. A 36, 5 (2018). 
${ }^{10}$ N. Nepal, N. Mahadik, L. Nyakiti, S. B. Qadri, M. J. Meh, J. Hite, and C. Eddy, Jr., Crystal Growth \& Design 13, 1485 (2013).

${ }^{11}$ M. F. J. Vos, G. Straaten, W. M. M. Kessels, and A. J. M. Mackus, J. Phys. Chem. C 122 (39), 22519 (2018).

${ }^{12}$ D. Shenai-Khatkhate, R. L. DiCarlo, R. A. Ware, J. Cryst. Growth 310, 2395 (2008).

${ }^{13}$ A. Koukitu, T. Taki, N. Takahashi, and H. Seki, J. Cryst. Growth 197, 99 (1999).

${ }^{14}$ Y.-N. Xu, W. Y. Ching, Phys. Rev. B: Condens. Matter. Mater. Phys. 48, 4335 (1993).

${ }^{15}$ W. Paszkowicz, R. Cerny, S. Krukowski, Powder Diffraction 18, 114 (2003).

${ }^{16}$ I. Yonenaga, M. Deura, X. Q. Wang et al., AIP Advances 5, 077131 (2015).

${ }^{17}$ A. Zubrilov, M. E. Shur, et al., John Wiley \& Sons, Inc. New York, 49 (2001).

${ }^{18}$ R. W. B. Gaydon, A. G. Pearse, The Identification of Molecular Spectra, Chapman \& Hall, London, (1984).

${ }^{19}$ C. Ozgit-Akgun, E. Goldenberg, A. K. Okyay, and N. Biyikli, J. Mater. Chem. C, 2014,2, 2123-2136

${ }^{20}$ V. Lebedev, V. Cimalla, J. Pezoldt, M. Himmerlich, S. Krischok, J. A. Schaefer, O. Ambacher, F. M. Morales, J. G. Lozano, and D. González, J. Appl. Phys. 100, 094902 (2006).

${ }^{21}$ R. Bazinette, J. Paillol, F. Massines, Plasma Sources Sci. Technol. 24, 055021 (2015).

${ }^{22}$ L. Yan-qin, B. De-cai, D. Lan-bo, Z. Xiu-ling, L. Zhi-sheng, L. Xue-hui, Spectroscopy and spectral analysis 35, 765 (2015).

${ }^{23}$ M. Boumerzoug, P. Mascher, P. Mascher, Plasma Chemistry and Plasma Processing 17, 2 (1997).

${ }^{24}$ C. Vandenabeele, M. Buddhadasa, P. Girard-Lauriault, R. Snyders, Thin Solid Films 630, 100 (2017).

${ }^{25}$ R. DiMundo, F. Palumbo, F. Fracassi, R. d'Agostino, Plasma Processes and Polym. 4, S21 (2007).

${ }^{26}$ A. Koukitu, N. Takahashi, and H. Seki, Jpn. J. Appl. Phys. 36, 136 (1997). 
${ }^{27}$ C. A. Arguello, D. L. Rousseau, and S. P. S. Porto, Physical Review 181, 1351 (1969).

${ }^{28}$ M. Yoshimoto, Y. Yamamoto, and J. Saraie, Phys. Stat. Sol. 7, 2794 (2003).

${ }^{29}$ J. Wang, Z. Li, P. Chen, W. Lu, T. Yao, Acta Materialia 55, 183 (2007).

${ }^{30}$ A. V. Kolobov J. Applied Physics 87, 2926 (2000).

${ }^{31}$ M. Liebhaber, B. Halbig, U. Bass, and J. Geurts, Phys. Rev. B 94, 235304 (2016).

${ }^{32}$ J. Bohn, P. Etchegoin, E. Le Ru, R. Xiang, S. Chiashi, and S. Maruyama, ACS Nano 4, $3466(2010)$.

${ }^{33}$ K. Torii, N. Usukura, A, Nakamura, T. Sota, S. Chichibu, T. Kitamura, and H. Okumura, Appl. Phys. Lett. 82, 6 (2003).

${ }^{34}$ L. F. Jiang, W. Z. Shen, H. F. Yang, H. Ogawa, and Q. X. Guo, Appl. Phys. A 78, 89 (2004). 